\title{
Youth Quality of Life Instrument-Research version (YQOL-R): psychometric properties in a community sample
}

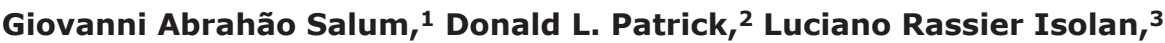 \\ Gisele Gus Manfro, ${ }^{4}$ Marcelo P. de Almeida Fleck ${ }^{5}$
}

\begin{abstract}
Objective: To test some psychometric properties of the Brazilian-Portuguese version of the Youth Quality of Life Instrument-Research (YQOL-R) in a community sample of Brazilian adolescents.

Methods: This is a cross-sectional community study conducted in six schools of the catchment area of a family health unit. From an original population of 2,754 students from 10 to 17 years old, we randomly selected 419 to answer the Brazilian-Portuguese version of the YQOL-R. We tested reliability, known group differences (using anxiety symptoms and bullying involvement), and factor structure.

Results: The YQOL-R showed a good internal consistency and had an adequate and expected known group differences with both bullying and anxiety. The factor structure of the conceptual model was partially supported by our analysis.
\end{abstract}

Conclusions: The Brazilian-Portuguese version of the YQOL-R showed sufficiently good psychometric properties. Further studies are needed in order to better investigate alternative configurations of the factor structure.

J Pediatr (Rio J). 2012;88(5):443-8: Health-related quality of life, patient reported outcome, quality of life, anxiety, bullying, validity.

\section{Introduction}

The validation of quality of life (QoL) and health-related quality of life (HRQOL) measures is being considered a research priority in child and adolescent mental health. ${ }^{1}$ The Youth Quality of Life Instrument - Research Version $(\mathrm{YQOL}-\mathrm{R})^{2}$ is an instrument that takes into consideration what adolescents themselves say that is important to their QoL. The instrument development has involved youth-centered models of qualitative research based upon subjective self-report and which are developmentally appropriate, using grounded theory approach. ${ }^{2}$ In addition, quantitative validity data have shown preliminary psychometric properties encouraging further research, ${ }^{3}$ and the instrument is already being used to measure HRQoL in pediatric samples. ${ }^{4-6}$ In spite of that, there are no studies aiming to demonstrate its psychometric proprieties in Brazilian samples.

The main objective of this study was to test some psychometric properties of the Brazilian Portuguese version of the YQOL-R in a community sample of Brazilian adolescents.

1. MD. Anxiety disorders program for Child and Adolescent Psychiatry (PROTAIA), Hospital de Clínicas de Porto Alegre (HCPA), Universidade Federal do Rio Grande do Sul (UFRGS), Porto Alegre, RS, Brazil. National Science and Technology Institute for Child and Adolescent Psychiatry (INPD), Brazil. Post-graduate Program in Medical Sciences, Psychiatry, HCPA, UFRGS, Porto Alegre, RS, Brazil.

2. PhD. Department of Health Services, University of Washington, Seattle, Washington, USA.

3. MD. PROTAIA, HCPA, UFRGS, Porto Alegre, RS, Brazil. Post-graduate Program in Medical Sciences, Psychiatry, HCPA, UFRGS, Porto Alegre, RS, Brazil.

4. MD, PhD. PROTAIA, HCPA, UFRGS, Porto Alegre, RS, Brazil. INPD, Brazil. Post-graduate Program in Medical Sciences, Psychiatry, HCPA, UFRGS, Porto Alegre, RS, Brazil.

5. MD, PhD. Post-graduate Program in Medical Sciences, Psychiatry, HCPA, UFRGS, Porto Alegre, RS, Brazil.

No conflicts of interest declared concerning the publication of this article.

Financial support: Giovanni Abrahão Salum Junior receives a CAPES doctoral scholarship. Luciano Isolan receives a CNPq doctoral scholarship. Gisele Gus Manfro and Marcelo Fleck receive a senior CNPq researcher scholarship. This paper was partially funded by the Brazilian government agencies FIPE-HCPA (08-017), FAPERGS (PRONEX 2009 - FAPERGS/CNPq 10/0018.3), and CNPq (483032/2007-7).

Suggested citation: Salum GA, Patrick DL, Isolan LR, Manfro GG, Fleck MP. Youth Quality of Life Instrument-Research version (YQOL-R): psychometric properties in a community sample. J Pediatr (Rio J). 2012;88(5):443-8.

Manuscript submitted Jan 16 2012, accepted for publication Mar 142012.

http://dx.doi.org/10.2223/JPED.2193 


\section{Methods}

This is a cross-sectional community study conducted in six public schools from the catchment area of the family health unit of Hospital de Clínicas de Porto Alegre, Brazil. We invited all 10- to 17-year-old students to participate in the study. The inclusion criterion involved being a student from one of the included schools regularly attending classes at that school in the period of the research. The original population of these schools comprised 2,754 adolescents; $217(7.9 \%)$ were not approached by the research team to answer the questionnaires due to school dropout, transference to another school or missing classes in the days when questionnaire responses were collected and when the rescue visit was performed, and 80 (3.2\%) refused participation and/or signed a dissent form, which was distributed for all parents and adolescents 2 weeks before the administration of the questionnaires. From the remaining 2,457 students, 419 were randomly selected to participate in this research, and there were no additional refuses. Scales were administered in the classroom, with careful supervision of the research team. Further details about sampling procedures can be found elsewhere. ${ }^{7}$ The study was approved by the Institutional Review Board and Ethics Committee of Hospital de Clínicas de Porto Alegre.

The YQOL-R is a self-rated 41 -item scale developed to evaluate self-perceived QoL in adolescents and comprises four domains: self (14 items), relationships (14 items), environment (10 items), and general QoL (three items). 2,3 The response scale is an 11-point scale with anchors at zero ("Not at all") and 10 ("A great deal or completely"). Higher scores represent better QoL. All domains have shown good internal consistency (Cronbach's alpha 0.77-0.96) and test-retest reliability (intraclass correlation coefficients $=0.74-0.85) \cdot{ }^{3}$ Discriminant validity with measures of depression, disability and attention deficit/ hyperactivity disorder has shown to be adequate. ${ }^{5}$

The SCARED is a 41-item self-report measure of child and adolescent anxiety during the past 3 months. Items are scored using a three-point scale. Final scores ranges from 0 to 82 , and higher scores reflect higher levels of anxiety. This scale has shown good psychometric properties. ${ }^{8}$

As in previous studies, ${ }^{9}$ the frequency of involvement in bullying and victimization during the last year was assessed after a previous definition of bullying, ${ }^{9}$ followed by examples of behaviors that are considered bullying and by the question: "Taking that definition and those examples into consideration, have you ever felt like you are being bullied at school"?

Sample size was defined using a subject-to-variable ratio of approximately 10:1.10 We used the Kaiser-Meyer-Olkin (KMO) to evaluate sampling adequacy and the Bartlett's test for sphericity to observe if the variables were highly correlated, in order to provide a reasonable basis for factor analysis. We tested internal consistency using the
Cronbach's alpha, and the construct validity using known group validity across SCARED percentiles and frequencies of bullying involvement. Principal component analysis with varimax rotation was used for exploratory factor solution, using the scree plot to define graphically the number of factors. We also used confirmatory factor analysis (CFA) for the four-factor solution of the original conceptual scale, using chi-square goodness-of-fit, root mean square error of approximation (RMSEA) and one of the baseline fit measures, and the Tucker-Lewis Index (TLI) ${ }^{11}$ as fit indices. A chi-square $>0.5$, a RMSEA $\leq 0.6$, and a TLI $>0.8-0.9$ were suggested as cutoffs for these indices, indicating good model fit. The analysis of variance (ANOVA) was performed to compare $\mathrm{YQOL}-\mathrm{R}$ scores between quartiles of anxiety symptoms according to SCARED and categories of bullying involvement. All tests were two-tailed, with an alpha value of 0.05 and a $95 \%$ confidence interval.

\section{Results}

From the 419 students, 209 (49.9\%) were female. The mean age was 13.9 years (standard deviation $=2.45$ ). Factor analysis with non-missing questions was available for 412 subjects. Frequencies and ranges indicated that all response choices were used and followed a normal distribution. Floor/ceiling effects were lesser than 50\% for all items.

KMO and Bartlett's tests satisfied the assumption for factor analysis. Cronbach's alpha for the 41 items was 0.931 ( 0.803 for the self domain, 0.885 for the relationship domain, 0.851 for the environmental domain, and 0.779 for the general QoL domain of the YQOL-R scale). Principal component analysis with varimax rotation was conducted to assess the underlying structure of the 41 items of the YQOL-R. Four factors were requested, based on graphical analysis of the scree plot. Results of the factor loadings by item and variance explanation are depicted in Table 1.

CFA of the original scale reveals mixed results: whereas chi-square test indicated lack of fit (chi-square $=1,834.8$, degrees of freedom $=768 ; p<0.001)$, other indices seem to show an acceptable model (RMSEA $=0.058$, TLI $=0.834$ )

In addition, a single factor principal component analysis was run on the four domain scores in order to assess whether the data supported the use of an overall score. The results of this analysis showed that a single factor explained $74.8 \%$ of the total variation in the domain scores with an eigenvalue of 2.99, hence supporting the use of an overall YQOL-R score.

Comparison between known groups of anxiety symptoms percentiles and bullying behaviors can be observed in Table 2. We can see a linear dose-response effect between both anxious symptoms and bullying involvement and YQOL-R scores in all domains evaluated. 
Table 1 - Factor loading for items of YQOL-R

\begin{tabular}{|c|c|c|c|c|c|c|c|}
\hline \multirow{2}{*}{ Item } & & & \multicolumn{4}{|c|}{ Factor loading } & \multirow[b]{2}{*}{ Comunality } \\
\hline & & & $\mathbf{I}$ & II & III & IV & \\
\hline REL13 & - & adults treat me fairly & $0.488^{*}$ & 0.226 & 0.370 & 0.028 & 0.427 \\
\hline REL14 & - & attention from family & $0.774^{*}$ & 0.213 & 0.192 & 0.036 & 0.682 \\
\hline REL15 & - & understood by parents & $0.775^{*}$ & 0.124 & 0.212 & 0.037 & 0.663 \\
\hline REL16 & - & useful to family & $0.702^{*}$ & 0.241 & 0.271 & 0.003 & 0.624 \\
\hline REL17 & - & family cares & $0.734^{*}$ & 0.230 & 0.083 & 0.053 & 0.602 \\
\hline REL18 & - & family encourages & $0.662^{*}$ & 0.341 & 0.104 & 0.009 & 0.565 \\
\hline REL19 & - & get along with parents & $0.817^{*}$ & 0.225 & 0.132 & -0.010 & 0.735 \\
\hline REL20 & - & participate in decisions & $0.656^{*}$ & 0.144 & 0.217 & -0.077 & 0.503 \\
\hline REL25 & - & satisfied with social life & $0.443^{*}$ & 0.365 & 0.290 & 0.255 & 0.479 \\
\hline GENQ & - & satisfied with life & $0.542^{*}$ & 0.403 & 0.205 & $0.234^{+}$ & 0.552 \\
\hline ENV29 & - & life is interesting & 0.393 & $0.427^{*}$ & 0.343 & -0.057 & 0.458 \\
\hline ENV30 & - & try new things & 0.184 & $0.689^{*}$ & 0.142 & -0.141 & 0.549 \\
\hline ENV31 & - & like neighborhood & 0.172 & $0.496^{*}$ & -0.015 & 0.220 & 0.324 \\
\hline ENV32 & - & forward to future & 0.108 & $0.659^{*}$ & 0.236 & -0.169 & 0.531 \\
\hline ENV33 & - & enough money & 0.288 & $0.470^{*}$ & 0.156 & 0.107 & 0.339 \\
\hline ENV34 & - & safe at home & 0.438 & $0.501^{*}$ & 0.071 & 0.084 & 0.455 \\
\hline ENV35 & - & good education & 0.193 & $0.668^{*}$ & 0.088 & -0.029 & 0.492 \\
\hline ENV36 & - & get information & 0.157 & $0.628^{*}$ & 0.280 & 0.010 & 0.498 \\
\hline ENV37 & - & enjoy learning & 0.165 & $0.681^{*}$ & 0.202 & -0.126 & 0.548 \\
\hline ENV38 & - & safe at school & 0.098 & $0.575^{*}$ & 0.172 & 0.003 & 0.370 \\
\hline REL23 & - & tell friends feelings & $0.104^{+}$ & $0.336^{*}$ & 0.322 & -0.061 & 0.231 \\
\hline REL24 & - & happy with friends & $0.164^{+}$ & $0.556^{*}$ & 0.152 & 0.278 & 0.436 \\
\hline REL26 & - & take part in activities & $0.310^{+}$ & $0.396^{*}$ & 0.301 & 0.052 & 0.346 \\
\hline REL27 & - & respect from peers & $0.210^{+}$ & $0.461^{*}$ & 0.388 & 0.057 & 0.410 \\
\hline GENQ & - & enjoy life & 0.366 & $0.564^{*}$ & 0.149 & $0.130^{+}$ & 0.491 \\
\hline GENQ & - & life is worthwhile & 0.412 & $0.517^{*}$ & 0.247 & $0.121^{+}$ & 0.513 \\
\hline SELF1 & - & keep trying & -0.022 & 0.200 & $0.440^{*}$ & -0.140 & 0.253 \\
\hline SELF2 & - & handle difficulties & 0.113 & 0.132 & $0.619^{*}$ & -0.027 & 0.415 \\
\hline SELF3 & - & able to do things well & 0.067 & 0.221 & $0.568^{*}$ & 0.041 & 0.378 \\
\hline SELF4 & - & good about self & 0.330 & 0.345 & $0.480^{*}$ & 0.116 & 0.472 \\
\hline SELF5 & - & important to others & 0.212 & 0.143 & $0.628^{*}$ & 0.026 & 0.461 \\
\hline SELF6 & - & comfortable with sexual feelings & 0.188 & 0.026 & $0.670^{*}$ & 0.148 & 0.506 \\
\hline SELF7 & - & enough energy & 0.164 & 0.343 & $0.547^{*}$ & -0.087 & 0.451 \\
\hline SELF8 & - & pleased with looks & 0.390 & 0.181 & $0.418^{*}$ & 0.035 & 0.361 \\
\hline SELF9 & - & comfortable with stress & 0.301 & 0.018 & $0.395^{*}$ & 0.273 & 0.322 \\
\hline SELF10 & - & okay to make mistakes & 0.131 & -0.001 & $0.330^{*}$ & 0.272 & 0.200 \\
\hline SELF11 & - & life has meaning & 0.394 & 0.187 & $0.532^{*}$ & 0.034 & 0.474 \\
\hline SELF12 & - & beliefs give strength & 0.225 & 0.289 & $0.513^{*}$ & -0.180 & 0.429 \\
\hline REL22 & - & role model & $0.082^{+}$ & 0.126 & 0.204 & $-0.590^{*}$ & 0.412 \\
\hline SELF21 & - & alone in life & 0.269 & 0.167 & $-0.043^{+}$ & $0.529^{*}$ & 0.382 \\
\hline SELF28 & - & left out & -0.078 & 0.031 & $0.162^{+}$ & $0.596^{*}$ & 0.388 \\
\hline \multicolumn{3}{|c|}{ Eigenvalues } & 6.362 & 6.088 & 4.659 & 1.618 & \\
\hline \multicolumn{3}{|c|}{$\%$ variance } & 15.518 & 14.850 & 11.364 & 3.948 & \\
\hline
\end{tabular}

Items in the table are sorted by the four extracted factors (I - extracted relationship factor; II- extracted environmental factor; III - extracted self factor; IV - a nonpreviously described factor) and are named respecting their original domains in the original study (SELF, question from the original self domain; ENV, question from the original environmental domain; GENQ, question from the original general quality of file domain; REL, question from the original relationship domain).

* Factor loading that represents new extracted factors.

$\dagger$ Items that mark higher factor loadings in extracted factors other than their original domains. 
Table 2 - Comparison of YQOL-R scores with SCARED percentiles and bullying victimization groups

\begin{tabular}{|c|c|c|c|c|c|c|c|c|c|}
\hline \multirow[b]{2}{*}{ Groups } & \multirow[b]{2}{*}{$\mathbf{n}$} & \multirow[b]{2}{*}{ Mean } & \multirow[b]{2}{*}{ SD } & \multicolumn{2}{|c|}{ ANOVA } & \multirow[b]{2}{*}{ Post-hoc* } & \multirow[b]{2}{*}{ MD } & \multicolumn{2}{|c|}{$95 \% \mathrm{CI}$} \\
\hline & & & & $\mathbf{F}$ & $\mathbf{p}$ & & & Lower & Upper \\
\hline \multicolumn{10}{|c|}{ SCARED percentile groups } \\
\hline \multicolumn{10}{|c|}{$\begin{array}{l}\text { General quality of life } \\
\text { domain score }\end{array}$} \\
\hline$<$ P25 & 102 & 87.84 & 18.57 & & & [Ref] & [Ref] & & \\
\hline P25-P50 & 102 & 83.55 & 20.34 & & & 0.130 & 4.30 & -1.27 & 9.87 \\
\hline P50-P75 & 112 & 80.67 & 18.86 & & & 0.010 & 7.18 & 1.73 & 12.63 \\
\hline > P75 & 100 & 73.97 & 23.09 & & & $<0.001$ & 13.87 & 8.27 & 19.47 \\
\hline Total & 416 & 81.52 & 20.78 & 8.356 & $<0.001$ & & & & \\
\hline \multicolumn{10}{|l|}{ Self domain score } \\
\hline$<\mathrm{P} 25$ & 102 & 73.14 & 16.06 & & & [Ref] & [Ref] & & \\
\hline P25-P50 & 102 & 66.44 & 15.83 & & & 0.002 & 6.69 & 2.42 & 10.97 \\
\hline P50-P75 & 112 & 63.64 & 14.24 & & & $<0.001$ & 9.50 & 5.32 & 13.68 \\
\hline > P75 & 100 & 57.68 & 16.09 & & & $<0.001$ & 15.46 & 11.16 & 19.75 \\
\hline Total & 416 & 65.22 & 16.43 & 17.272 & $<0.001$ & & & & \\
\hline \multicolumn{10}{|c|}{ Relationship domain score } \\
\hline$<$ P25 & 102 & 75.14 & 13.86 & & & [Ref] & [Ref] & & \\
\hline P25-P50 & 102 & 69.77 & 17.80 & & & 0.025 & 5.37 & 0.68 & 10.05 \\
\hline P50-P75 & 112 & 68.66 & 16.12 & & & 0.006 & 6.48 & 1.90 & 11.06 \\
\hline > P75 & 100 & 62.66 & 19.91 & & & $<0.001$ & 12.48 & 7.77 & 17.19 \\
\hline Total & 416 & 69.08 & 17.52 & 9.118 & $<0.001$ & & & & \\
\hline \multicolumn{10}{|c|}{ Environmental domain score } \\
\hline$<$ P25 & 102 & 83.38 & 17.23 & & & [Ref] & [Ref] & & \\
\hline P25-P50 & 102 & 80.87 & 18.77 & & & 0.281 & 2.51 & -2.06 & 7.09 \\
\hline P50-P75 & 112 & 79.73 & 14.92 & & & 0.109 & 3.65 & -0.82 & 8.12 \\
\hline > P75 & 100 & 75.79 & 15.39 & & & 0.001 & 7.59 & 3.00 & 12.19 \\
\hline Total & 416 & 79.96 & 16.77 & 3.652 & 0.013 & & & & \\
\hline \multicolumn{10}{|c|}{ Total quality of life score } \\
\hline$<$ P25 & 102 & 79.87 & 14.14 & & & [Ref] & [Ref] & & \\
\hline P25-P50 & 102 & 75.16 & 16.31 & & & 0.024 & 4.72 & 0.63 & 8.81 \\
\hline P50-P75 & 112 & 73.17 & 13.53 & & & 0.001 & 6.70 & 2.70 & 10.70 \\
\hline > P75 & 100 & 67.53 & 15.45 & & & $<0.001$ & 12.35 & 8.24 & 16.46 \\
\hline Total & 416 & 73.95 & 15.44 & 11.957 & $<0.001$ & & & & \\
\hline \multicolumn{10}{|c|}{ Bullying victimization groups } \\
\hline $\begin{array}{l}\text { General quality of life } \\
\text { domain score }\end{array}$ & & & & & & & & & \\
\hline Not bullied & 243 & 83.15 & 21.57 & & & [Ref] & {$[$ Ref] } & & \\
\hline Sometimes bullied & 158 & 79.27 & 19.74 & & & 0.071 & 3.88 & -0.34 & 8.09 \\
\hline Frequently bullied & 15 & 70.74 & 24.01 & & & 0.027 & 12.41 & 1.44 & 23.38 \\
\hline Total & 416 & 81.23 & 21.11 & 3.579 & 0.029 & & & & \\
\hline Self domain score & & & & & & & & & \\
\hline Not bullied & 243 & 67.66 & 16.59 & & & [Ref] & {$[$ Ref $]$} & & \\
\hline Sometimes bullied & 158 & 62.80 & 15.94 & & & 0.003 & 4.86 & 1.61 & 8.10 \\
\hline Frequently bullied & 15 & 50.86 & 10.43 & & & $<0.001$ & 16.81 & 8.35 & 25.26 \\
\hline Total & 416 & 65.21 & 16.54 & 10.452 & $<0.001$ & & & & \\
\hline Relationships domair & & & & & & & & & \\
\hline Not bullied & 243 & 71.53 & 17.04 & & & [Ref] & [Ref] & & \\
\hline Sometimes bullied & 158 & 65.98 & 18.17 & & & 0.002 & 5.55 & 2.03 & 9.06 \\
\hline Frequently bullied & 15 & 56.99 & 17.53 & & & 0.002 & 14.54 & 5.39 & 23.69 \\
\hline Total & 416 & 68.90 & 17.81 & 8.419 & $<0.001$ & & & & \\
\hline Environmental doma & & & & & & & & & \\
\hline Not bullied & 243 & 81.94 & 17.85 & & & [Ref] & [Ref] & & \\
\hline Sometimes bullied & 158 & 76.83 & 15.91 & & & 0.003 & 5.11 & 1.71 & 8.51 \\
\hline Frequently bullied & 15 & 77.64 & 10.26 & & & 0.340 & 4.30 & -4.55 & 13.15 \\
\hline Total & 416 & 79.85 & 17.07 & 4.491 & 0.012 & & & & \\
\hline Total quality of life sc & & & & & & & & & \\
\hline Not bullied & 243 & 76.07 & 15.97 & & & [Ref] & [Ref] & & \\
\hline Sometimes bullied & 158 & 71.22 & 14.92 & & & 0.002 & 4.85 & 1.74 & 7.95 \\
\hline Frequently bullied & 15 & 64.06 & 11.98 & & & 0.004 & 12.01 & 3.93 & 20.10 \\
\hline Total & 416 & 73.80 & 15.71 & 7.798 & $<0.001$ & & & & \\
\hline
\end{tabular}

[Ref] = reference category; $\mathrm{MD}=$ mean difference; $\mathrm{SD}=$ standard deviation; $95 \% \mathrm{Cl}=95 \%$ confidence interval.

* Post hoc test performed using least significant differences. 


\section{Discussion}

In the present study, we were able to investigate some psychometric properties of the YQOL-R in a community sample of 10 - to 17-year-old adolescents. The YQOL-R has shown a good internal consistency and a linear doseresponse effect with known group differences (for both anxiety and bullying). The factor structure has shown mixed results, and further studies with larger samples are needed.

There is a trend towards greater consideration of patient reported outcomes, including HRQoL. QoL measures can be used for several reasons: service planning, estimating cost-effectiveness of treatments, and measuring how well a healthcare system is meeting the health needs of a given population. They can also provide a better picture for service managers about the differences between patient groups, resulting in evidence-based resource allocation, and, for some researchers, are considered the gold standard of clinical decision making. ${ }^{1}$

Several instruments are being constructed to measure QoL in children and adolescents. A recent study has found at least 14 measures of general QoL for children and adolescents, ${ }^{12}$ but very few are fully validated in different cultures, and there are few validated scales to measure the QoL of children and adolescents in Brazil. ${ }^{13-15}$ We decided to use the YQOL-R and to validate it for Brazilian-Portuguese because of its well-conducted process of conceptual development ${ }^{2}$ and quantitative research showing good psychometric properties. ${ }^{3}$

In our study, factor structure achieves only partial support for the original conceptual four-factor solution (environmental, self, relationship and general QoL domains). Both exploratory and confirmatory analysis demonstrated mixed results. Our exploratory analysis has shown that items related to friendship have higher loadings in the environmental domain rather than in the relationship domain. This misfit is reasonable for schoolchildren, since the environmental domain has a lot of items related to school environment. In addition, as expected, the general QoL domain did not load into a separate domain.

Regarding CFA, the lack of fit of the chi-square test may be discounted, since a significant chi-square itself is not a reason to modify the model. ${ }^{11}$ Therefore, further research is needed to confirm factor structure and to investigate the use of CFA alternative proposed factors.

Our study has some limitations. First, we have assessed some psychometric properties of YQOL-R, but not all of them. Second, the lack of an independent sample did not allow us to evaluate a CFA model for our findings from the exploratory analysis. Finally, our age range is large compared to our sample size and therefore we were not able to evaluate if psychometric properties are stable over different age ranges.
The concept and measures of QoL in adolescents still needs further research. Studies investigating psychometric properties are needed in order to provide valid and reliable instruments to better integrate QoL data into clinical research. The YQOL-R has shown sufficiently good psychometric properties to encourage further research investigations and clinical use.

\section{Acknowledgements}

Giovanni Abrahão Salum Junior receives a CAPES doctoral scholarship. Luciano Isolan receives a CNPq doctoral scholarship. Gisele Gus Manfro and Marcelo Fleck receive a senior CNPq researcher scholarship. This paper was partially funded by the Brazilian government agencies FIPE-HCPA (08-017), FAPERGS (PRONEX 2009 - FAPERGS/ CNPq 10/0018.3) and CNPq (483032/2007-7).

\section{References}

1. Coghill D, Danckaerts M, Sonuga-Barke E, Sergeant J; ADHD European Guidelines Group. Practitioner review: quality of life in child mental health - conceptual challenges and practical choices. J Child Psychol Psychiatry. 2009;50:544-61.

2. Edwards TC, Huebner CE, Connell FA, Patrick DL. Adolescent quality of life, part I: conceptual and measurement model. J Adolesc. 2002;25:275-86.

3. Patrick DL, Edwards TC, Topolski TD. Adolescent quality of life, part II: initial validation of a new instrument. J Adolesc. 2002;25:287-300.

4. Findling $R L$, Childress $A C$, Cutler $A J$, Gasior M, Hamdani $M$, Ferreira-Cornwell MC, et al. Efficacy and safety of lisdexamfetamine dimesylate in adolescents with attentiondeficit/hyperactivity disorder. J Am Acad Child Adolesc Psychiatry. 2011;50:395-405.

5. Topolski TD, Edwards TC, Patrick DL, Varley P, Way ME, Buesching DP. Quality of life of adolescent males with attention-deficit hyperactivity disorder. J Atten Disord. 2004;7:163-73.

6. Isolan L, Pheula G, Salum GA Jr, Oswald S, Rohde LA, Manfro GG. An open-label trial of escitalopram in children and adolescents with social anxiety disorder. J Child Adolesc Psychopharmacol. 2007;17:751-60.

7. Salum GA, Isolan LR, Bosa VL, Tocchetto AG, Teche SP, Schuch I, et al. The multidimensional evaluation and treatment of anxiety in children and adolescents: rationale, design, methods and preliminary findings. Rev Bras Psiquiatr. 2011;33:181-95.

8. Isolan L, Salum GA, Osowski AT, Amaro E, Manfro GG. Psychometric properties of the Screen for Child Anxiety Related Emotional Disorders (SCARED) in Brazilian children and adolescents. J Anxiety Disord. 2011;25:741-8.

9. Nansel TR, Overpeck M, Pilla RS, Ruan WJ, Simons-Morton B, Scheidt P. Bullying behaviors among US youth: prevalence and association with psychosocial adjustment. JAMA. 2001;285:2094-100.

10. Bryant FB, Yarnold PR. Principal components analysis and exploratory and confirmatory factor analysis. In: Grimm LG, Yarnold PR, eds. Reading and understanding multivariate analysis. Washington, DC: American Psychological Association Books; 1995. p. 99-136.

11. Garson GD. Structural Equation Modeling. In: Statnotes: Topics in Multivariate Analysis; 2009. http://faculty.chass.ncsu.edu/ garson/pa765/statnote.htm. Access: 22/03/2012. 
12. Janssens L, Gorter JW, Ketelaar M, Kramer WL, Holtslag HR. Health-related quality-of-life measures for long-term follow-up in children after major trauma. Qual Life Res. 2008;17:701-13.

13. Assumpção FB Jr, Kuczynski E, Sprovieri MH, Aranha EM. Quality of life evaluation scale (AUQEI - Autoquestionnaire Qualité de Vie Enfant Imagé). Validity and reliability of a quality of life scale for children 4 to 12 years-old. Arq Neuropsiquiatr. 2000;58:119-27.

14. de Souza FM, Molina J, Terreri MT, Hilário MO, Len CA. Reliability of the Pediatric Quality of Life Inventory - Healthcare Satisfaction Generic Module 3.0 version for the assessment of the quality of care of children with chronic diseases. J Pediatr (Rio J). 2012;88:54-60.
15. Klatchoian DA, Len CA, Terreri MT, Silva M, Itamoto C, Ciconelli RM, et al. Quality of life of children and adolescents from São Paulo: reliability and validity of the Brazilian version of the Pediatric Quality of Life Inventory version 4.0 Generic Core Scales. J Pediatr (Rio J). 2008;84:308-15.

Correspondence:

Giovanni Abrahão Salum

Hospital de Clínicas de Porto Alegre

Ramiro Barcelos, 2350, sala 2202

CEP 90035-003 - Porto Alegre, RS - Brazi

Tel./Fax.: +55 (51) 3359.8094

E-mail: gsalumjr@gmail.com 